\title{
Incidence of invasive cervical cancer in the Swiss canton of Vaud, and a note on screening
}

\author{
FABIOLEVI, ${ }^{1}$ CARLOLA VECCHIA, ${ }^{2}{ }^{3}$ VAN-CONGTE, ${ }^{1}$ AND FELIX GUTZWILLER ${ }^{2}$ \\ From ${ }^{1}$ Registre Vaudois des Tumeurs, Institut Universitaire de Médecine Sociale et Préventive, Lausanne ${ }^{2}$ Institut \\ Universitaire de Médecine Sociale et Préventive, Bugnon 17, Lausanne, Switzerland; and ${ }^{3}$ Istituto di Ricerche \\ Farmacologiche "Mario Negri", Via Eritrea 62, Milan, Italy.
}

\begin{abstract}
Age adjusted incidence rates (World standard) from invasive cervical cancer in the Swiss canton of Vaud decreased from 17.7/100 000 in 1968-70 to 9.9/100 000 in 1983-85. The decline was substantial in younger middle age, but no appreciable trend was observed in women over 70 . This is consistent with available interview based information on the pattern of cervical screening in the Swiss population. Although there was no organised screening programme in Switzerland, over $80 \%$ of women aged $20-44$ and $65 \%$ of those aged $45-64$ reported one or more screening smears over the previous 3 years, compared to only $22 \%$ of women aged 65 or over. In the last calendar period, there was an apparent increase in the incidence of invasive cervical cancer (from 2.5 to $6.1 / 100000$ ) in women aged 25-29. Although based on small absolute numbers, this is in agreement with incidence and mortality data from other countries, and may therefore confirm a change in risk factor exposure in younger women.
\end{abstract}

Studies on trends in incidence and mortality from cervical cancer in various countries and age groups in relation to the various screening policies adopted have provided important evidence to support and quantify the role of screening programmes in the reduction of mortality from cervical cancer. The most convincing evidence has come from the Nordic countries, where the fall in mortality from cancer of the cervix has been greater in countries most widely covered by organised screening programmes (Iceland, Sweden and Finland, as compared to Denmark or Norway), and, within each country, has been restricted to the age groups covered by screening. ${ }^{2}$

Besides screening, analyses of trends in invasive cervical cancer incidence and mortality may prove useful in order to understand the changing pattern of risk factor exposure in subsequent generations. For instance, a substantial increase in death rates from cervical cancer has been observed among British women born since $1935 .{ }^{34}$ Similar upward trends have been observed in Queensland, Australia, ${ }^{56}$ but not in various other western countries, including the United States. ${ }^{78}$

In order to provide further information on the issue, we examined incidence data from the Cancer Registry of the Swiss canton of Vaud, in relation to available data on screening patterns in the Swiss population.

\section{Methods}

Cervical cancer incidence data for the period 1974-85 were abstracted from the population based Vaud Cancer Registry file, which includes data concerning incident cases of malignant neoplasms in the Canton (which has a population, according the 1980 Census, of about 530000 inhabitants). ${ }^{910}$

Information collected by the register includes general demographic characteristics of the patient (age, sex, municipality of residence), site and histological type of the tumour according to the standard International Classification of Diseases for Oncology, ${ }^{11}$ and time of diagnostic confirmation.

Incidence data for the period 1968-73 were derived from an ad hoc retrospective incidence survey conducted by the director of the Cancer Registry. ${ }^{12} 13$ Estimates of the corresponding incidence rates were obtained through the application of registration rules and the utilisation of sources which were the most comparable with those routinely available to the local cancer Registry.

The present series comprises 868 new cervical cancer primaries (ICD-O T : 180.0-180.9). In situ as well as other non-specified uterine neoplasms were excluded. Histological confirmation was performed in about $90 \%$ of the cases. 
Age specific as well as overall and 35-64 years age standardised incidence rates (Vaud 1980, and World standard population) were computed.

Information on cervical smear utilisation in Switzerland was derived from the Swiss National Health Survey "SOMIPOPS" which has been described elsewhere. ${ }^{14}$ Briefly, a random sample of 5836 adults aged 20 or over was selected within strata of nationality (Swiss citizens $v$ foreign residents) and (for Swiss citizens only) municipality of residence, combining a simple random sampling without replacement and a cluster sampling (at least eight individuals for each municipality). Data were collected through a self-administered questionnaire, followed by a personal interview arranged for each respondent. The overall participation rate (completed questionnaire plus interview) was $73 \%$ (70\% for Swiss citizens, $85 \%$ for foreign residents), thus leaving a total of 4255 subjects (3419 Swiss and 836 foreigners).

Along with information about socio-demographic characteristics, general lifestyle habits, current health status, history of selected diseases and frequency of health service utilisation, data were collected on cervical screening history (ever screened and time since last smear). Validation and checks for data reliability were obtained, whenever possible, from independent integrating sources (eg, health insurance data).

\section{Results}

The age curves of cervical cancer incidence in three subsequent 6 year calendar periods are plotted in the figure. Consistent and substantial falls in incidence

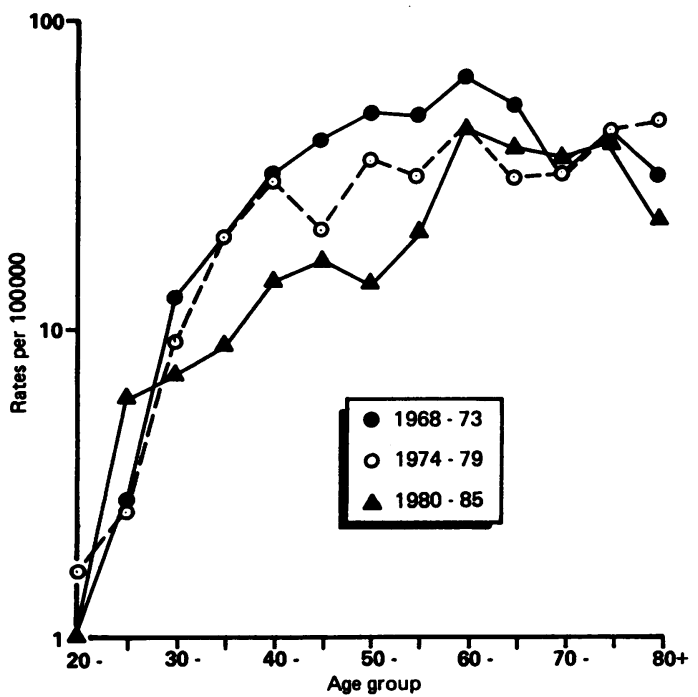

Figure Trends in age-specific incidence rates of invasive carcinoma of the cervix uteri in the Swiss Canton of Vaud, 1968-1985. were evident in women aged 30 to 64. No apparent change in rates was observed above age 64 , while in younger women (before age 30) there was an indication of increased incidence over the most recent calendar years considered: in the age group 25-29, seven cases were registered (6.1/100 000 women) over the period 1980-85, as compared with three in each of the two preceding 6 year periods (2.5/100 000 women). Overall age standardised (on the World standard population) incidence rates fell from $17 \cdot 7 / 100000$ in $1968-70(n=188)$, to 9.9 in $1983-85(n=131)$, and truncated rates ( 35 to 64 years) from $52 \cdot 5(n=124)$ to $19 \cdot 2(n=62)$ (table 1). Marked downward trends were evident up to the early 1980 s, but rates have apparently levelled off around the 1980-82 rates over more recent calendar years.

Information derived from the 1981-83 Swiss National Health Survey ${ }^{14}$ on pattern and frequency of cervical smear utilisation is given in table 2 . Over $80 \%$ of younger women (age 20 to 44 ) had one or more screening smears within the last 3 years, and only $13.5 \%$ were never screened. The proportion of women not reporting a recent smear increased in older middle age, particularly in women over 65 , among whom only $22.5 \%$ reported a smear over the last 3 years.

\section{Discussion}

The present study showed an approximately $40 \%$ decrease in incidence rates from invasive cervical cancer between the late 1960s and the early 1980s in the Swiss canton of Vaud. This was concentrated in younger middle age, while no apparent fall was evident above 70 years. This is consistent with available information on the pattern and frequency of utilisation of cervical screening among Swiss women, which covered most of the population in younger middle age, but less than $25 \%$ of women over 65 .

Assuming an overall coverage of the population of about $65 \%$ at a 3 year interval, as derived from interview based data, the estimated decline in incidence is comparable with the Scandinavian data: the falls in mortality between 1963 and 1982 were $50 \%$ and $34 \%$ in Finland and Sweden, where the estimated coverages were $75 \%$ and $70 \%$ respectively, and the recommended screening intervals 5 and 4 years. $^{2}$

The major difference between the Swiss and the Scandinavian situation (with the exception of Norway) ${ }^{2}$ is that there is no organised programme in Switzerland, screening being totally spontaneous and only occasionally assisted by information campaigns. Nonetheless, the increased screening frequency in Swiss women has probably led to an appreciable impact on invasive cervical cancer rates, though this is far from the optimal effect obtained in countries such as Iceland where there is an organised nationwide 
Table 1 Trends in age standardised (Vaud 1980 and World Standard Population) incidence rates* for cervical cancer cases from the canton of Vaud, Switzerland, 1968-1985

\begin{tabular}{|c|c|c|c|c|c|c|}
\hline \multirow[b]{3}{*}{ Period } & \multicolumn{3}{|c|}{ Overall rates } & \multicolumn{3}{|c|}{ Truncated $(35-64)$ rates } \\
\hline & \multicolumn{2}{|l|}{ Adjusted on } & \multirow[b]{2}{*}{$\begin{array}{l}\text { Number } \\
\text { of cases }\end{array}$} & \multicolumn{2}{|l|}{ Adjusted on } & \multirow[b]{2}{*}{$\begin{array}{l}\text { Number } \\
\text { of cases }\end{array}$} \\
\hline & Vaud 1980 & World & & Vaud 1980 & World & \\
\hline $1968-70$ & $25 \cdot 0$ & $17 \cdot 7$ & 188 & 43.5 & $42 \cdot 5$ & 124 \\
\hline 1971-73 & $19 \cdot 8$ & 14.7 & 155 & 34.9 & $35 \cdot 4$ & 103 \\
\hline $1974-76$ & 18.5 & $13 \cdot 2$ & 146 & $33 \cdot 2$ & $33 \cdot 3$ & 97 \\
\hline 1977-79 & $17 \cdot 7$ & $11 \cdot 4$ & 142 & $26 \cdot 0$ & 25.4 & 77 \\
\hline $1980-82$ & $12 \cdot 7$ & 8.9 & 106 & 18.4 & 18.5 & 56 \\
\hline $1983-85$ & 15.5 & 9.9 & 131 & 19.6 & $19 \cdot 2$ & 62 \\
\hline
\end{tabular}

* Per 100000 women

Table 2 Percentage distribution of women included in the 1981-83 Swiss National Health Survey* according to age group and time since last smear. Number of women in parentheses.

\begin{tabular}{|c|c|c|c|c|c|}
\hline \multirow[b]{2}{*}{ Age } & \multicolumn{5}{|c|}{ Time since last smear } \\
\hline & $\begin{array}{l}<l y r \\
\%(n)\end{array}$ & $\begin{array}{l}1-3 y r s \\
\%(n)\end{array}$ & $\begin{array}{l}>3 y r s \\
\%(n)\end{array}$ & $\begin{array}{l}\text { Never } \\
\text { screened } \\
\%(n)\end{array}$ & $\begin{array}{l}\text { Total } \\
\%(n)\end{array}$ \\
\hline $20-44$ yrs & $59 \cdot 0(605)$ & $21 \cdot 2(218)$ & $6.2 \quad(64)$ & 13.5 (139) & $100(1026)$ \\
\hline $45-64$ yrs & 38.9 (245) & $24.8(156)$ & $21 \cdot 3(134)$ & $15.1 \quad(95)$ & $100 \quad(630)$ \\
\hline$\geq 65 \mathrm{yrs}$ & $11.6 \quad(33)$ & 10.9 & $26 \cdot 1 \quad(74)$ & $51 \cdot 4(146)$ & $100 \quad(284)$ \\
\hline Total & $45 \cdot 5(883)$ & $20.9(405)$ & $14 \cdot 0$ & $19.6(380)$ & $100(1940)$ \\
\hline
\end{tabular}

* Reference 14

screening programme, resulting in an $84 \%$ fall in mortality from 1965 to $1982^{2}$; and it has probably also been achieved at substantially greater cost (considering, for instance, that $59 \%$ of women aged $20-44$ reported a screening smear within the year before interview). ${ }^{15}$

These inferences between trends in cervical cancer incidence and screening patterns are in our view reasonable in terms of confirming the evidence from other countries. Nonetheless, some caution is advised in interpreting the data, on account of limitations due to the relatively small absolute numbers and to the application of interview based data on cervical screening obtained from a national sample to the population of the canton of Vaud.

A further interesting suggestion emerging from this study is the apparent increase in invasive cervical cancer incidence among younger women (aged 25 to 30) over the most recent calendar years. Although based on very small numbers (seven cases), this change in rates is in agreement with the suggestion from an age/period/cohort analysis on Swiss national death rates ${ }^{16}$ as well as with mortality data from Britain ${ }^{34}$ or incidence data from Australia, ${ }^{5}$ and therefore deserves careful monitoring over the coming years.

The contribution of the Swiss League against Cancer, Bern, is gratefully acknowledged.

Address for correspondence and reprints: Fabio Levi, Registre Vaudois des Tumeurs, Institut Universitaire de Médecine Sociale et Préventive, CHUV BH-06, 1011 Lausanne, Switzerland.

\section{References}

${ }^{1}$ Day NE. Effect of cervical cancer screening in Scandinavia. Obstet Gynecol 1984; 63: 714-8.

${ }^{2}$ Laara E, Day NE, Hakama M. Trends in mortality from cervical cancer in the Nordic countries; association with organized screening programmes. Lancet 1987; i: 1247-9.

${ }^{3}$ Yule R. Mortality from carcinoma of the cervix. Lancet 1978, i: 1031-2.

4 Doll R. Invasive cervical cancer and combined oral contraceptives. $\mathrm{Br}$ Med J 1985; 290: 1210.

${ }^{5}$ Armstrong B, Holman D. Increasing mortality from cancer of the cervix in young Australian women. Med J Aust 1981; 1: 460-2.

${ }^{6}$ Bourne RG, Grove W. Invasive carcinoma of the cervix in Queensland. Med J Aust 1983; 1: 156-8.

${ }^{7} \mathrm{Chu}$ J, White E. Decreasing incidence of invasive cervical cancer in young women. Am J Obstet Gynecol 1987; 157: $1105-7$.

${ }^{8}$ McKay FW, Hanson MR, Miller RW. Cancer mortality in the United States: 1950-1972. Bethesda, MD: NCI Monograph, 1982: 59.

${ }^{9}$ Levi F. Vaud Cancer Registry statistics 1975-1977. In: Waterhouse J, Muir CS, Shanmugaratnam K, Powell J, eds. Cancer incidence in five continents. Vol 4. Lyon: International Agency for Research on Cancer (IARC Scientific Publications, No 42), 1982: 546-9.

${ }^{10}$ Levi F. Le cancer dans la population vaudoise. Incidence et mortalité 1979-1983. (Cancer statistics from the population of the canton of Vaud, Switzerland. Incidence and mortality, 1979-1983). Lausanne: Registre Vaudois des Tumeurs-Institut Universitaire de Médecine Sociale et Préventive, Lausanne, 1985.

${ }^{11}$ International Classification of Diseases for Oncology, ICD-O. Ist ed. Geneva: WHO, 1976. 
12 Levi F. Les tumeurs gynécologiques dans le canton de Vaud. Evolution entre 1940 et 1976. (Thèse Méd., Fac. Méd., Lausanne). Milan: Ariminum, 1979.

${ }^{13}$ Levi F. Aspects épidémiologiques du cancer du col utérin dans le canton de Vaud. Considérations sur l'influence de la pratique du dépistage. Méd Hyg 1980; 38: 480-6.

14 Collaborative Group (Gutzwiller F, Leu RE, Schulz HR, Schroeter R, and Zemp E.) The Swiss Health Survey Project (SOMIPOPS): an example of a data collection effort from various sources. Soz Praeventivmed 1985; 30: 76-9.
${ }^{15}$ IARC Working Group on Evaluation of Cervical Screening Programmes. Screening for squamous cervical cancer: duration of low risk after negative results of cervical cytology and its implication for screening policies. Br Med J 1986; 293: 659-64.

${ }^{16}$ Levi F, La Vecchia C, Decarli A, Randriamiharisoa A. Effects of age, birth cohort and period of death on Swiss cancer mortality, 1951-1984. Int J Cancer 1987; 40: 439-49.

Accepted for publication November 1988 